\title{
MENINGKATKAN MINAT DAN POTENSI GENERASI MILENIAL KHUSUSNYA SISWA-SISWI SMK DARUSSALAM UNTUK MEMULAI BISNIS ONLINE DENGAN SISTEM DROPSHIP
}

\author{
Derita Qurbani, Sri Mardiana, Riski Dwi Nugroho \\ Universitas Pamulang \\ Email: dosen01582@unpam.ac.id
}

\begin{abstract}
This dedication is entitled to increase the interest and potential of millennial generation, especially students of SMK Darussalam to start an online business with a dropship system in Ciputat, South Tangerang. The purpose of this service is to help students generate income to support their daily needs so as to ease the burden on parents. The method of implementing this service is carried out in several activities, namely the survey stage, namely the socialization carried out by compiling various things to be delivered at the time of service activities that will be carried out which include: preparation of material to be given, preparation of material delivery schedule, division of tasks of the service team and survey to the location devotion. The socialization phase is before the community service activities are carried out first, the socialization phase is to make a friendly meeting with the principal, to convey the aims and objectives of this service. At this stage also carried out the fabric of cooperation and determine the schedule of service activities. The implementing team of community service activities are 5 lecturers from the Faculty of Economics majoring in management. The dedication team provided material on increasing the interest and potential of millennial generation, especially students of SMK Darussalam to start an online business with a dropship system in Ciputat, South Tangerang. The training and materials were delivered by Pamulang University lecturers. The conclusion of this dedication is that during the process the students were enthusiastic and focused in participating in community service activities held by Pamulang University lecturers.
\end{abstract}

Keywords: Online Business, Dropship System, Students of SMK Darussalam

\begin{abstract}
Abstrak
Pengabdian ini berjudul meningkatkan minat dan potensi generasi millenial khususnya siswa-siswi SMK Darussalam untuk memulai bisnis online dengan sistem dropship di Ciputat Tangerang Selatan. Tujuan pengabdian ini adalah membantu siswa-siswi dalam menghasilkan pendapatan untuk menunjang kebutuhan sehari-hari mereka sehingga dapat meringankan beban orang tua. Metode pelaksanaan pengabdian ini dilakukan dalam beberapa kegiatan yaitu tahap survei yaitu sosialisasi dilakukan dengan menyusun berbagai hal yang akan disampaikan pada saat kegiatan pengabdian yang akan dilakukan yang meliputi: penyusunan materi yang
\end{abstract}


akan diberikan, penyusunan jadwal pemberian materi, pembagian tugas tim pengabdian dan survei ke lokasi pengabdian. Tahap sosialisasi yaitu sebelum kegiatan pengabdian dilaksanakan terlebih dahulu dilakukan tahap sosialisasi yaitu melakukan silaturahmi dengan kepala sekolah, untuk menyampaikan maksud dan tujuan pengabdian ini. Pada tahap ini juga dilakukan jalinan kerjasama dan menentukan jadwal kegiatan pengabdian. Tim pelaksana kegiatan pengabdian pada masyarakat adalah dosen Fakultas Ekonomi jurusan manajemen sebanyak 5 orang. Tim pengabdian memberikan materi tentangmeningkatkan minat dan potensi generasi millenial khususnya siswa-siswi SMK Darussalam untuk memulai bisnis online dengan sistem dropship di Ciputat Tangerang Selatan. Pemberikan pelatihan dan materi disana disampaikan oleh dosen Universitas Pamulang. Kesimpulan dari pengabdian ini adalah selama proses tersebut para siswa antusias dan fokus dalam mengikuti kegiatan pengabdian masyarakat yang diadakan oleh dosen Universitas Pamulang.

Kata Kunci : Bisnis Online, Sistem Dropship, Siswa-siswi SMK Darussalam

\section{A. PENDAHULUAN}

Seiring dengan perkembangan zaman maka kebutuhan manusia sebagai mahluk sosial pun meningkat.Tak terkecuali untuk para remaja seperti siswa - siswi yang membutuhkan gaya hidup yang menjadi trend saat ini, oleh karena itu mereka membutuhkan penghasilan untuk menunjang kehidupannya tersebut sehingga meringankan beban orangtua mereka. Untuk itu mereka perlu dibekali, dengan berbagai macam problem solving untuk memenuhi kebutuhan tersebut. Salah satu problem solving oleh pengabdian masyarakat kali ini adalah tentang berbisnis online tanpa mengeluarkan modal yaitu hanya dengan menggunakan blokblok pribadi seperti Facebook, Instagram, Twitter, Whatsapp, BBM dan media online lainnya dengan menggunakan sistem dropship.

Dropship adalah sebuah sistem penjulan produk secara online dimana si penjual/pengecer tidak harus memiliki modal besar atau produk sendiri. Sistem dropship berbeda dengan sistem Reseller yang mengharuskan penjual/pengecer untuk membeli produk kepada si supplier atau pemilik barang untuk stok, lalu kemudian dijual ke konsumen dengan mengambil keuntungan dari selisih harga barang. Selain itu penjual//pengecer tidak perlu repot mengerjakan proses pengiriman barang kepada si pembeli karena supplier yang akan menegerjakannya. Istimewanya lagi pada bungkus barang yang dikirm ke pembeli akan ditulis bahwa barang dikirm oleh penjual/pengecer jadi kredibilitas kita sebagai dropsipper tetap terjaga dengan baik.

Dengan adanya materi ini diharapkan bisa membuka pemikiran siswa - siswi untuk mendapatkan penghasilan demi menunjang kebutuhannya secara mandiri dan membantu orang tua mereka. Oleh karena itu, Perlu adanya dukungan dari pihak Yayasan untuk menjalankan pelatihan ini agar tersampaikan dengan maksimal.

\section{B. METODE PELAKSANAAN KEGIATAN}

Tempat penelitian ini dilaksanakan pada SMK Darussalam Kecamatan Ciputat, Kota Tangerang Selatan.Waktu Pelaksanaan Kegiatan : Hari Selasa, Kamis, Jumat Tanggal 27, 29, dan 30 November 2018. Rincian acara pelaksanaan kegiatan pengabdian kepada masyarakat adalah sebagai berikut: 
Selasa, 27 November 2018

\begin{tabular}{|l|l|l|l|}
\hline No & \multicolumn{1}{|c|}{ Waktu } & \multicolumn{1}{|c|}{ Susunan Acara } & \multicolumn{1}{c|}{ Pemateri/ Penanggung Jawab } \\
\hline 1 & $08.00-08.45$ & Pembukaa Acara & MC (Sri Mardiana, S.E., M.M) \\
\hline 2 & $08.45-09.00$ & Pembacaan Al-Quran & Bpk. Ustad.Komarudin \\
\hline 3 & $08.45-09.00$ & Sambutan Ketua Pelaksana & Derita Qurbani, S. Psi., M.M \\
\hline 4 & $09.00-09.30$ & $\begin{array}{l}\text { Sambutan Kepala Sekolah } \\
\text { SMK Darussalam }\end{array}$ & Yang mewakili Ibu Priyanti \\
\hline 5 & $09.30-09.45$ & Pengenalan Acara Pelatihan & Agus Supriatna,SE.M.M \\
\hline 6 & $09.45-10.00$ & Penutup & MC (Sri Mardiana, S.E., M.M) \\
\hline 7 & 10.00 & Selesai & Panitia \\
\hline
\end{tabular}

Kamis, 29 November 2018

\begin{tabular}{|c|c|c|c|}
\hline No & Waktu & Susunan Acara & Pemateri/PenanggungJawab \\
\hline 1 & $09.00-09.15$ & Pembukaan & MC (Sri Mardiana, S.E., M.M) \\
\hline 2 & 09.15-09.45 & Pengarahan Ketua Pelaksana & Derita Qurbani, S. Psi., M.M \\
\hline 3 & $09.45-11.00$ & $\begin{array}{l}\text { Materi "Meningkatkan minat } \\
\text { dan Potensi Generasi Milenial } \\
\text { Khususnya Siswa-siswi SMK } \\
\text { Darussalam Untuk Memulai } \\
\text { Bisnis Online dengan Sistem } \\
\text { Dropship". }\end{array}$ & $\begin{array}{l}\text { Pembicara dari Dosen Unpam } \\
\text { Jamaludin, S.E.I., M.Ec.Dev }\end{array}$ \\
\hline 4 & $11.15-11.45$ & Sesi tanya jawab dan doorprize & Roni Heryanto, S.E., M.M \\
\hline 5 & $11.45-12.00$ & Penutup & MC (Sri Mardiana, S.E., M.M) \\
\hline 6 & $12.00-13.00$ & $\begin{array}{l}\text { Sholat dan Makan Siang } \\
\text { Bersama }\end{array}$ & Panitia \\
\hline 7 & 13.00 & Selesai & Panitia \\
\hline
\end{tabular}

Sabtu, 30 November 2018

\begin{tabular}{|c|c|c|c|}
\hline No & Waktu & SusunanAcara & Pemateri/PenanggungJawab \\
\hline 1 & $09.00-09.30$ & $\begin{array}{l}\text { Pembukaan Dan Review } \\
\text { Materi }\end{array}$ & MC (Sri Mardiana, S.E., M.M) \\
\hline 2 & $09.30-10.30$ & $\begin{array}{l}\text { Materi Tambahan "Praktek } \\
\text { Pelaksanaan Bisnis Online } \\
\text { dengan Sistem Dropship" }\end{array}$ & Nurmin Arianto, SE,MM \\
\hline 3 & $10.30-11.00$ & $\begin{array}{l}\text { Sesi tanya jawab dan } \\
\text { doorprize }\end{array}$ & Riski Dwi Nugroho,SE.M.M \\
\hline 4 & $11.00-11.45$ & Pemberian Sovenir & Panitia \\
\hline 5 & $11.45-12.00$ & Penutupan Acara & MC (Sri Mardiana, S.E., M.M) \\
\hline 6 & $12.00-13.00$ & $\begin{array}{l}\text { Sholat dan Makan Siang } \\
\text { Bersama }\end{array}$ & Panitia \\
\hline 7 & 13.00 & Selesai & Panitia \\
\hline
\end{tabular}




\section{HASIL DAN PEMBAHASAN}

Pelaksanan kegiatan PKM ini dilakukan oleh 3 (tiga) orang tim pengabdi dengan pokok bahasan yang disampaikan mengenai: "Meningkatkan minat dan Potensi Generasi Milenial Khususnya Siswa-siswi SMK Darussalam Untuk Memulai Bisnis Online dengan Sistem Dropship". Semua materi dapat disampaikan dengan detil. Kegiatan yang diawali dengan ceramah dan demonstrasi ini kemudian dilanjutkan latihan. Acara kemudian dilanjutkan sesi tanya jawab. Berbagai pertanyaan diajukan secara antusias oleh para peserta dalam sesi tanya jawab.

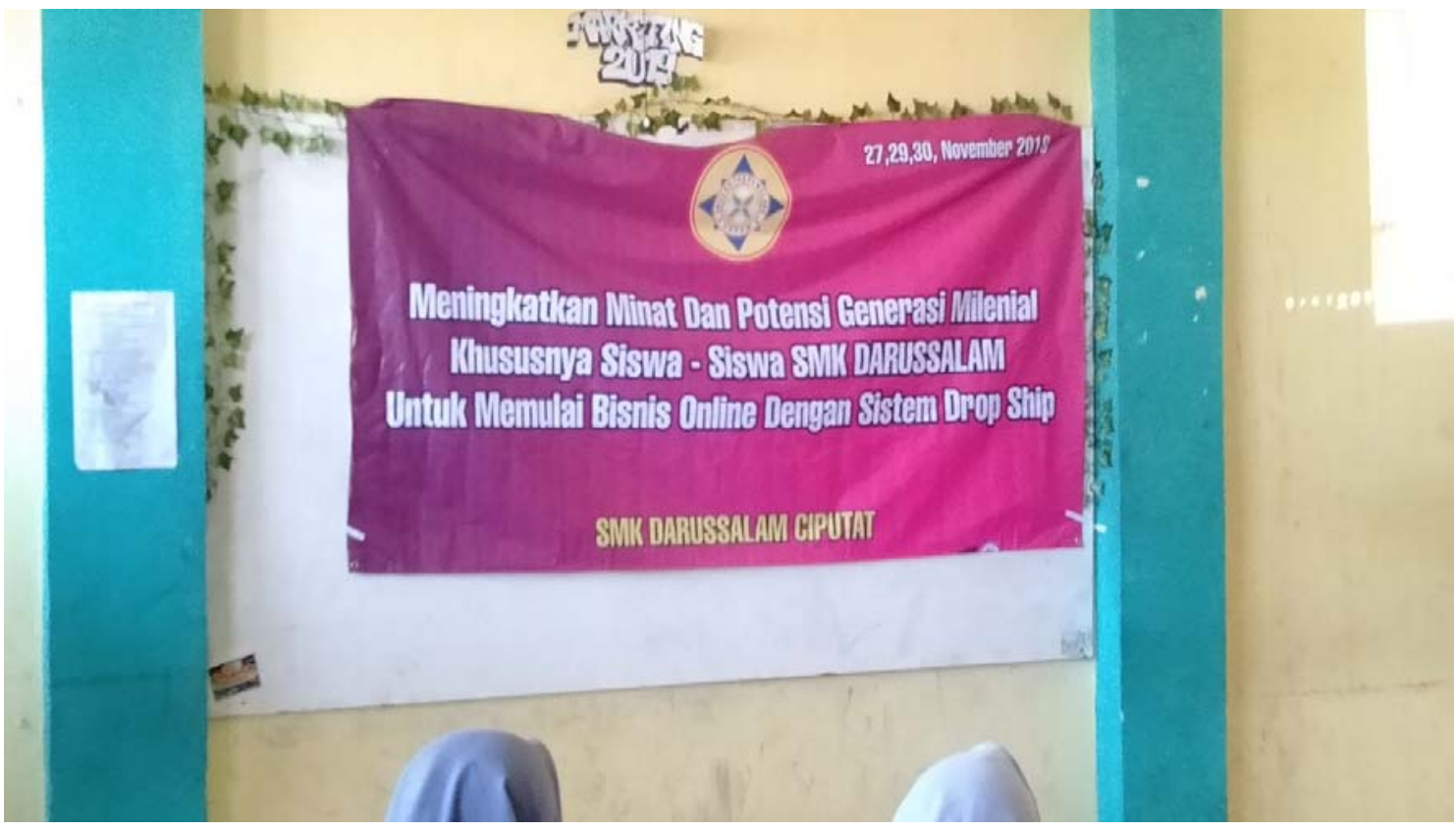

Gambar 1.Tema Kegiatan

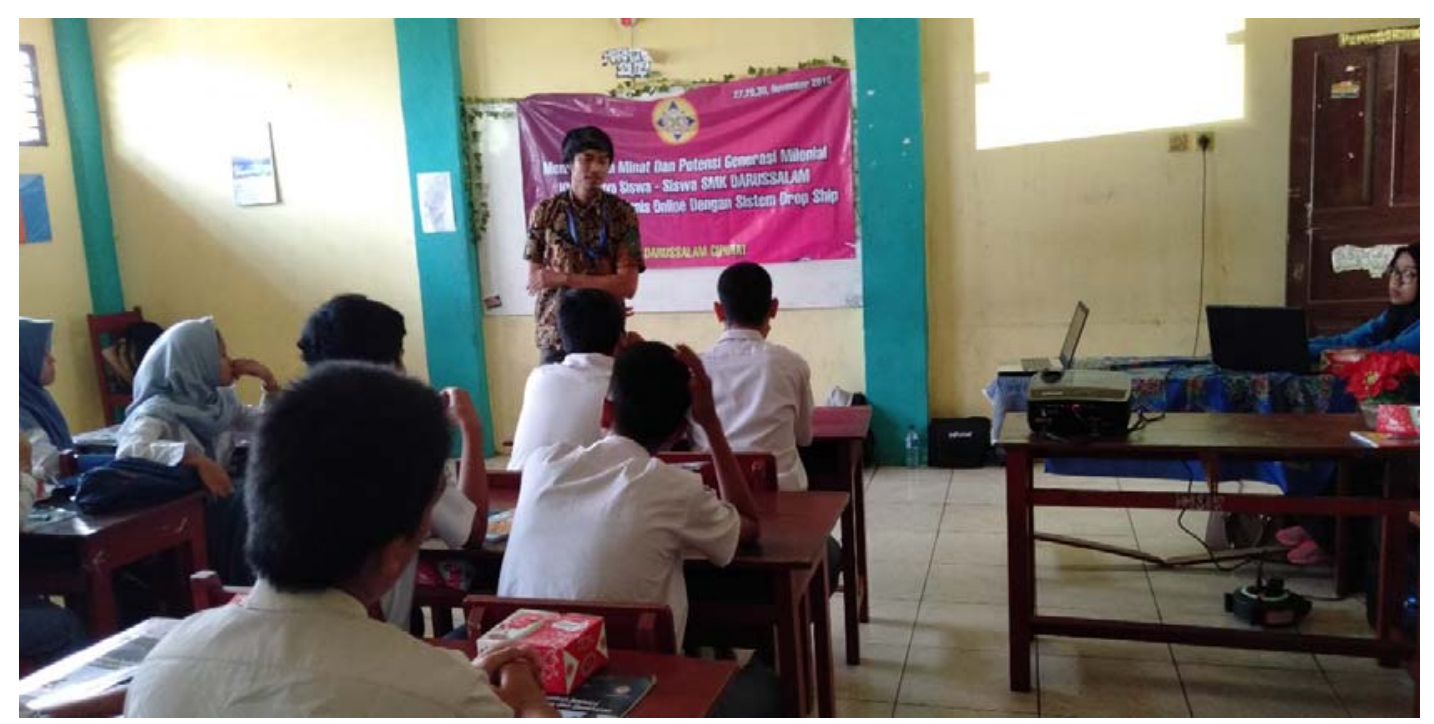

Gambar 2. Penyampaian Materi 
Penyampaian materi dan diskusi yang disampaikan oleh Bpk. Jamaludin, S.E.I., M.Ec.Dev kepada siswa-siswi SMK Darussalam Ciputat.

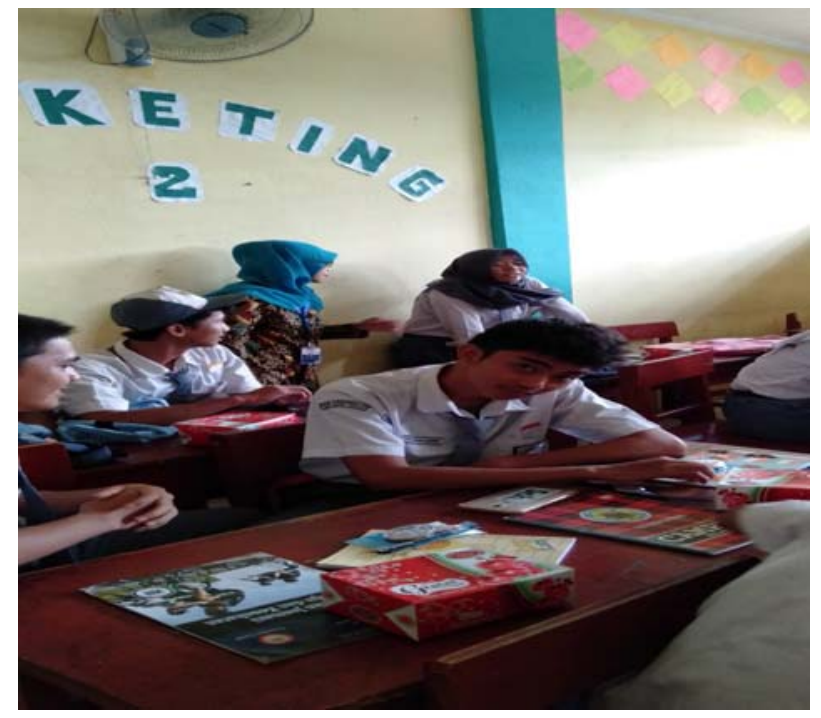

Gambar 3. Sesi Tanya jawab setelah proses penyampaian materi

\section{KESIMPULAN}

Pelaksanaan kegiatan Pengabdian Kepada Masyarakat oleh Lembaga Penelitian dan Pengabdian Masyarakat (LPPM) Universitas Pamulang yang dilakukan oleh dosen-dosen program studi Manajemen telah berjalan dengan lancar dan mendapat sambutan hangat dari tempat pelaksanaan kegiatan ini. Dalam laporan kegiatan ini mungkin banyak kekurangan yang ada, untuk itu kami berharap masukan dan kritikan dalam rangka perbaikan untuk kegiatan-kegiatan pengabdian masyarakat di masa yang akan datang. Semoga kegiatan pengabdian masyarakat ini dapat bermanfaat bagi siswa-siswi SMK Darussalam Ciputat.

Akhirnya, kami mengucapkan terimakasih kepada seluruh pihak yang telah mendukung kegiatan yang kami laksanakan dan kami mohon maaf apabila dalam laporan ini banyak ditemukan kekurangan.

\section{DAFTAR PUSTAKA}

Çelik, H., \& Harwanto, U. N. The Development Of Appropriate Teaching Material To 5E Teaching Model That Examines The Projectile Motion.

Maddinsyah, A., Fauzi, I., \& Barsah, A. (2019). Peran Teknologi Dalam Mengembangkan Potensi Diri Bagi Santri Di Yayasan Pembangunan Masyarakat Sejahtera Kelurahan Kedaung Pamulang Tangerang Selatam-Banten. Jurnal Pengabdian Dharma Laksana, 1(2), 259-266.

Sina, I., Maryunani, B. J., \& Harahab, N. (2017). Analysis of total economic value of ecosystem mangrove forest in the coastal zone Pulokerto Village District of Kraton Pasuruan Regency. International Journal of Ecosystem, 7(1), 1-10.

Susanto, S., \& Iqbal, M. (2019). Pengabdian Kepada Masyarakat Dalam Sinergitas Akademisi Dan TNI Bersama Tangkal Hoax Dan Black Campaign. CARADDE: Jurnal Pengabdian Kepada Masyarakat, 2(1). 